\title{
Change and Unity: Research on the "Modular" Design Method of Decorative Patterns on Bronze Ritual Vessels
}

\author{
Shunren Luo \\ Jingdezhen Ceramic Institute \\ Jingdezhen, China
}

\begin{abstract}
According to the book Ten Thousand Things: Module and Mass Production in Chinese Art, the "modular" design method has been used throughout all aspects of Chinese traditional ware design. Bronze ritual vessels, as the main part of bronze wares in Xia, Shang and Zhou Dynasties, their decoration system is also characterized by module, that is, different decorations appropriate for different parts and surfaces of bronze ritual vessels can be produced through various combination of a certain number of decorative matrixes and units. Based on the "modular" design method, this paper combs and analyzes the design methods for decorative patterns on bronze ritual vessels.
\end{abstract}

Keywords - bronze ritual vessels; decorative patterns; modular

\section{INTRODUCTION}

As the early ritual vessels used by the nobility in sacrifice activities for their ancestors in Xia, Shang and Zhou Dynasties, bronze ritual vessels can be found in a great variety of styles and forms with complex decoration, mainly including cooking vessels, food containers, drinking vessels, water containers, etc. As a token of power and status of the nobility, ritual vessels are used by the ruling class to identify the social class, superiors or inferiors, reflecting the ritual system of that period, which is so called "qi cang yu li" meaning rite concealed under the vessels (The Spring and Autumn Annals. the Second Year of Cheng of Lu Kingdom), so ritual vessel is also called as "li qi" or "yi qi" in Chinese. Compared with bronze wares excavated in other regions of ancient Eurasia, Chinese bronze ritual vessels have distinguishing features, as a result of cultural characteristics of Xia, Shang and Zhou Dynasties-developed patriarchal clan system. In addition, the well developed smelting and casting technology for bronze wares had laid a solid material and technical foundation for the production and development of bronze ritual vessels. In China, the design of styles and decorative patterns of the bronze ritual vessels is not only to meet the demands of daily life but to cater for the solemn sacrifice ceremony. In a word, the above facts are a strong statement that ancient Chinese bronze culture of all forms are originated in foreign countries and it has been developed independently in China.

As one of the Confucian classics, the Book of Rites records that sacrifice ceremony is considered as an event of vital important and an essential element of "li". In ancient China, noble rulers declare that they are the Sons of Heaven and govern the country by its will. In this way, they endow their power with the will of divinity and, therefore, make sacrifices to Heaven and supernatural beings to beg them to bless and protect their reign. Owing to the hierarchical difference among the noble rulers, using bronze ritual vessels shall conform to certain hierarchical standards, which means that different ritual vessels stand for different social status. As a result, the bronze ritual vessels shall be designed with recognizable distinguishing features so as to exhibit status difference of the users. To reach such purpose, an effective approach is to apply the "modular" design method.

\section{DEVELOPMENT AND EVOLUTION OF DECORATIVE PATTERNS ON BRONZE RITUAL VESSELS}

At the early Shang Dynasty, bronze ware had been in the initial development stage, when the bronze wares have obvious characteristics in the type, that is, raw and plain and without the distinct decoration property required for "li qi". Some of them are plain in the surface without decoration, and even large bronze wares are decorated mainly with monolayer raised Taotie patterns without shading.

From the late Shang Dynasty to the early Western Zhou Dynasty, the bronze ware had tended to be mature, when the bronze wares were produced with a great variety of types using more exquisite foundry technique. Most bronze wares have the property of "li qi" with solemn shapes and the implications of political and religious significance. Bronze ritual vessels are decorated mostly with fine patterns of clouds and lighting as the shading and other decorative patterns covering the surface. For example, heliciform fret is interspersed with Taotie patterns, kuilong, kuifeng patterns. The main figures of such patterns mostly are mysterious animals which combine with the vessels, giving people a sense of weird and changeable. Such decoration is the token of power, will and dignity of the ruler at this period, as it creates a solemn, awe-inspiring and even terrifying atmosphere so that the bronze ritual vessel are intensified in the social function and also have high wareistic value.

With the reform of social system, from the late Western Zhou Dynasty to the middle of Spring and Autumn Period, the 
property of bronze vessels as ritual and musical instruments has gradually changed. They were no longer decorated with the images of mysterious and terrifying animals such as Taotie patterns and kuilong patterns but with flexible and plain Qiequ vein, multi-rings veins, Chuilin veins, dragon patterns, waves, etc.

At the Spring and Autumn period with collapsed ritual, the bronze ware had lost its former property as "li qi" and its decorative patterns had changed a lot and focused on delicate geometric patterns together with actual animal patterns. In the middle of Spring and Autumn Period, some new techniques were created such as stamping method and lost wax process and complex Panhui and Panchi stripes were very popular at that time; red bronze and gold mosaics crafts appeared in Yan, Zhao and Cai, etc. counties; inscription of bird characters in $\mathrm{Wu}$, Yue, Chu, etc. countries.

\section{MEANING OF "MODUlE"}

In the 1990s, Lothar Ledderose, a professor in East Asia art history of Heidelberg University, proposed the concept of "module" during the research of Chinese art. According to him, Chinese have created a surprising number of works of art since the beginning of history. For instance, ten tons of bronze wares were excavated in a tomb of the 5th century BC; seven thousand terra-cotta warriors excavated in Qin Shihuang Mausoleum of 3rd century BC; thousands of lacquer plates made in the 1st century; wood pagodas built with about 30,000 pieces of wood components that were independently processed in the 11th century; from the 17 th to 18 th century, China imported billions of chinaware. These achievements were mainly credited to the Chinese production system based on assembly of standard components. Such components can be prefabricated in quantity and also can be assembled quickly in different combination ways, by which infinitely varied units can be generated from the limited general components. Such components are called as "module" in Ten Thousand Things: Module and Mass Production in Chinese Art.

\section{IV. "Module SysteM” AND THE DESIGN OF DECORATIVE PATTERNS ON BRONZE RITUAL VESSELS}

According to the professor Ledderose's interpretation of "module", it can be known that such design method based on the permutation and combination of independent components is referred to as "modular" which leads to a module system for the design and manufacture of all kinds of artistic works. In terms of ancient bronze ritual vessels, module system is associated with the design of decorative pattern on their surfaces.

According to the above analysis of the development and evolution of decorative patterns on bronze ritual vessels, it can be found that, in the period from Shang Dynasty to early Western Zhou Dynasty, such decorative patterns were much more complicated and attractive, applying various design methods. Therefore, the decorative patterns on typical bronze wares in this period are expected to be discussed in detail.

\section{A. Design Method Based on Combination of Modules of Different Numbers}

As components can be replaced over the course of design, modules, therefore, have a certain flexibility. As main and typical patterns, Taotie patterns have strong political and religious meanings. Bronze ritual vessels are made in various kinds and decorated with different Taotie patterns too, as shown in "Fig. 1" and "Fig. 2".

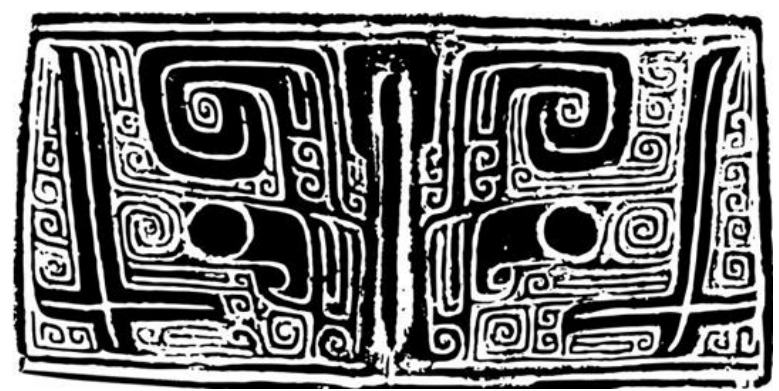

Fig. 1. Taotie pattern rubbing

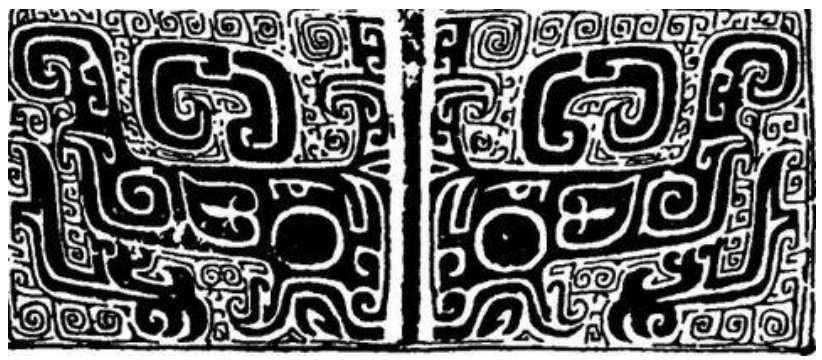

Fig. 2. Taotie pattern rubbing.

For the two Taotie patterns shown in "Fig. 1" and "Fig. 2", it can be found that the left and right parts of each Taotie pattern are almost in mirror symmetry, but there are still differences in the shading throughout the vessel surface if you watch carefully. Through further observation, it can be found that the horn at the right side is up wrapped much than that at the left side. These phenomena reveal that decorative patterns on the vessels are made manually instead of mechanical reproduction.

By observing various Taotie patterns, it can be found that each beast-face vein is actually composed of several parts, which means that the image is assembled as whole using independent modules including nose, eyes, eyebrow, ears, horns, upper and lower jaws, body, forefoots with sharp claws, etc. During the design of specific Taotie patterns, several modules might be omitted, for instance, compared with "Fig. 2", "Fig. 1" has no ears, lower jaw, body and forefoot, but still with the main pattern of Taotie with remarkable Taotie characteristics. From the facial images of the above two Taotie patterns, we can see that modules are not only in limited quantity but appear in fixed form or type. For example, independent modules such as eyes, eyebrow and horns, of which types are changing and not more than ten. Therefore, thousands types of Taotie patterns appeared in Shang and Zhou Dynasties are made through different combination of these modules. 


\section{B. Design Method of Patterns Proper for Images}

According to the analysis of Chinese characters wordformation in Ten Thousand Things: Module and Mass Production in Chinese Art, for every Chinese character we know, its strokes and radicals or the independent Chinese character can be adjusted in its size and scale with the writing place, so it has a certain adaptability. Similarly, elements of a Taotie pattern also can be adjusted with the space of its carrier. A typical example is Fangyi that is a kind of ancient Chinese vessel for keeping wine and prevailed from late Shang Dynasty to the middle of Western Zhou Dynasty. Fangyi is characterized by rectangular body with a lid, straight mouth, straight stomach and ring foot. The lid is tectiform with small top and big bottom, and each side of the ring foot has a breach. Besides, there are also some Fangyi with lower stomach plumped such as the cloned version of Fangyi that is exhibited in the Museum of East Asian Art "Fig. 3 ", due to its special shape, its section is in rectangular shape of which the front and back sides are a little wider than those at the right and left sides so the face images at the left and right sides in the Taotie pattern are a bit narrower and longer than those at the front and back sides. Different shapes and areas of the image on different parts of vessel lead to the variety of the pattern, for example, orbits of the Taotie pattern at the left and right sides of the vessel are omitted, just as the parts sticking out from the body and below the tail, which are omitted too. In addition, the kuilong image at the mouth edge and ring foot at the side of the vessel are a little shorter than that at the front and back sides. Highly characteristic decorative patterns are those on the surfaces of trapezoid vessels, "Fig. 4". It can be seen that general rectangular shape of Taotie patterns is changed in certain areas where the patterns are against the Taotie image, of which the body is parallel to the hypotenuse of the trapezoid, and claws parallel to the jaw. Taotie patterns on the narrow delta-shaped area seem to be smaller and more flat than those on other areas. In addition, for example, the omitted orbits of Taotie appear in the delta-shaped area of both sides of the lid, but part of Taotie body has to be entirely omitted due to the limitation of the shape of the surface, such as the paws that are in the both sides of the delta-shaped area before "Fig.5". Such phenomenon reveals that the design and application of Taotie patterns on different parts of the bronze wares are constricted by some rules and practice, and although combination and shape are not changeless, different parts of the Taotie patterns are not arranged randomly. For instance, above the eyes are the horns which are not likely to appear at the sides of the eyes, and under the eyes is jaw, and under the body are paws with barbs, and the bridge of the nose at the middle divides the Taotie figure into two parts which are almost symmetric. The design method of patterns has to be the one that can make the sizes and scales of different components of the Taotie patterns suitable for the sizes and shapes of the decorations surfaces.

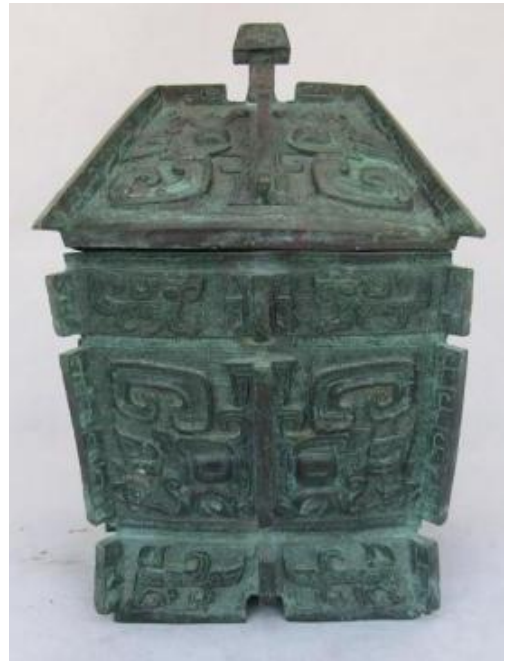

Fig. 3. Fangyi.

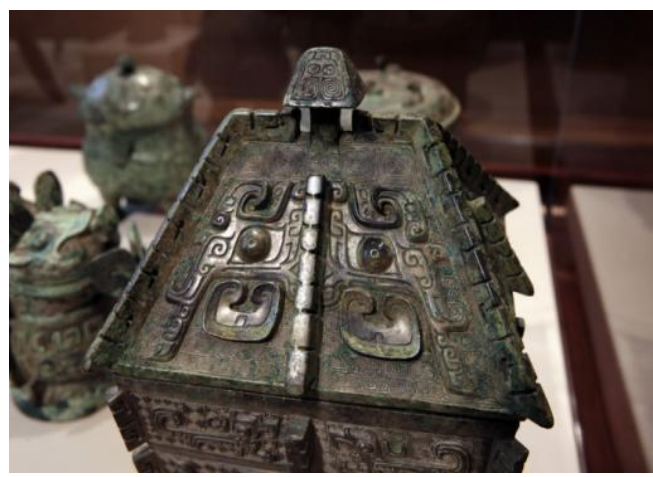

Fig. 4. Fangyi.

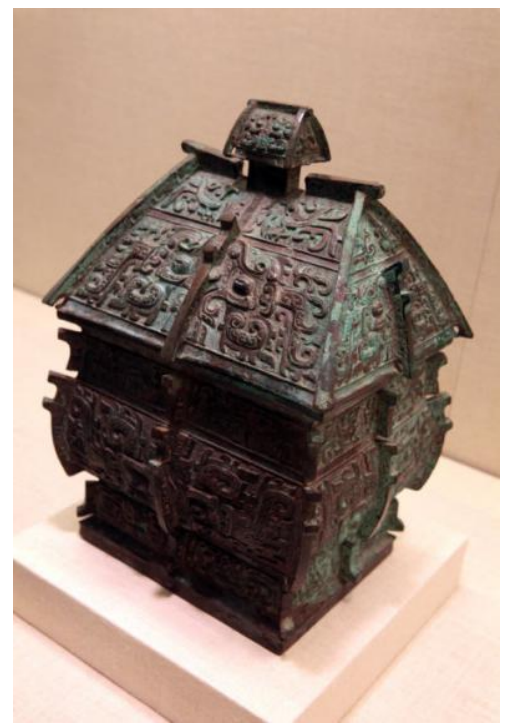

Fig. 5. Fangyi. 


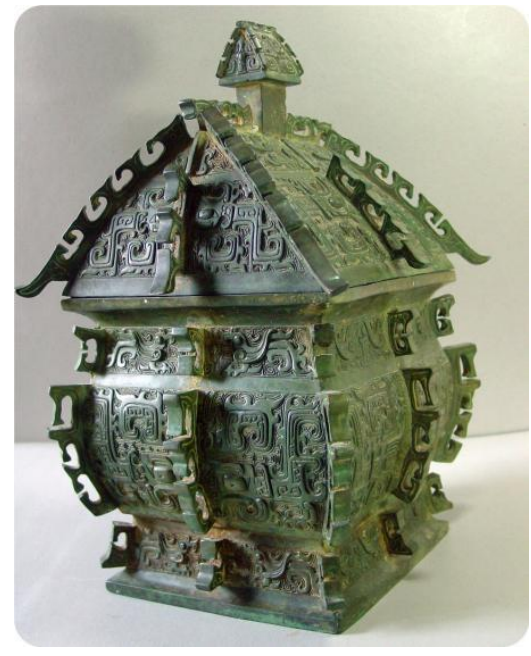

Fig. 6. Fangyi

\section{Design Method Based on the Reasonable Application of Auxiliary Pattern}

In late Shang Dynasty and early Zhou Dynasty, bronze wares sprung up as "li qi", and the decoration of them changed from plain surface almost without patterns to patterns mostly throughout the whole ware body. Notably, there were heliciform fret with distinct base among elements of the Taotie pattern, and such patterns were usually used as decorative shading for bronze ritual vessels to highlight the main pattern "Fig. 6". The reasonable application of auxiliary pattern reflects in that when the number and size of modules of the main pattern change, shading can be used to weaken the difference arising out of such change. For example, in the above Fangyi, compared with the Taotie patterns on the deltashaped area of lid of the vessel, those at the front side changed in the size and number of the modules of the main pattern, but uniform shading is used to decrease such difference to create the unity in visual. Lines of different thickness of the frets form neat and uniform texture, and nevertheless, the number, size, total number and position of each fret is changeable and flexible. Therefore, fret, as the auxiliary designed pattern, is capable of fill all kinds of spaces with given sizes and shapes uniformly and reasonably.

\section{CONCLUSION}

In general, the design of decorative patterns on the bronze ritual vessels in Shan and Zhou Dynasties expresses the beauty in form of change and unity. Owing to the fact that the decorative patterns are formed by different modules that have varied content and theme, this is the change the design reflects. However, such change has certain rules and modes, as it has to adapt to different vessel types to make it as a whole, but also has to create a uniform decorative effect based on the design of patterns on different modules. By studying the types of bronze ritual vessels, due to many similar vessels, it can be found that there is no limitless room for the designers of the bronze ritual vessels to unleash their creativity. In order to make the user of bronze ritual vessels can recognize which is theirs, the designer is expected to find a new design method based on the pre-set framework of given style and shape of a bronze ware to fill different parts of the vessel with different decorative patterns. Such measure is a important mean to distinguish the bronze ritual vessels belonging to different individuals. Additionally, the designer adjusts and combines various modules in different parts of the vessel to make them match with the shape and scale. In this way, various decorative patterns on bronze ritual vessels are generated, showing the world the unique artistic charm over the design of decorative patterns for bronze ritual vessels.

\section{REFERENCES}

[1] (German) Lothar Ledderose. Ten Thousand Things: Module and Mass Production in Chinese Art, Sanlian Bookstore, 2005.

[2] Huang Zongxian. History of Chinese Fine Art, People's Fine Arts Publishing House, 2004.

[3] (Japanese) HAYASHI Minao. Patterns of Divinity and Beast. Ancient Chinese Divinities, Sanlian Bookstore, 2016.

[4] (American) Wu Hong. Ten Questions in Art History, Sanlian Bookstore, 2016.

[5] (American) Wu Hong. Art in Etiquette, Sanlian Bookstore, 2016. 